\title{
Dokuz Eylül Üniversitesi Tıp Fakültesi Tıpta Uzmanlık Eğitimi Programlarına İlişkin Eğitici ve Öğrenci Geribildirimleri
}

\section{Trainers and Trainee Feedback on Residency Training Programs in Dokuz Eylül University Medical Faculty}

Gamze Çapa Kaya ${ }^{I}$, Şule Koluaçık ${ }^{2}$, Neslihan Aktaş3 ${ }^{3}$ Berna Musal

${ }^{1}$ Dokuz Eylül Üniversitesi Tıp Fakültesi Nükleer Tıp Anabilim Dalı, İzmir

${ }^{2}$ Dokuz Eylül Üniversitesi Tıp Fakültesi, Izmir

${ }^{3}$ Dokuz Eylül Üniversitesi Tıp Fakültesi Tıp Eğitimi Anabilim Dalı, İzmir

\author{
Anahtar Sözcükler: \\ Program değerlendirme, \\ geribildirim, \\ uzmanlık eğitimi \\ Keywords: \\ Program evaluation, \\ feedback, residency \\ training \\ Gönderilme Tarihi \\ Submitted:17.05.2018 \\ Kabul Tarihi \\ Accepted: 06.06.2018
}

\section{ÖZET:}

Amaç: Uygulanan eğitim programlarının, eğiticiler ve öğrenciler tarafindan sürekli ve sistematik olarak değerlendirilmesi ve elde edilen bulgular 1şığında güncellenerek geliştirilmesi önem taşımaktadır. Fakültemizde mezuniyet sonrası eğitim programları eğiticiler ve tıpta uzmanlık öğrencileri(TUÖ) tarafindan her yıl Haziran ayında, mezuniyet sonrası eğitim kurulu tarafından geliştirilmiş olan geri bildirim formları ile değerlendirilmektedir. Bu çalışmada beş yıllık değerlendirme bulgularının sunulması amaçlanmaktadır.

Gereç ve Yöntem: Öğrenciler 30 maddeden ve eğiticiler ise altı maddeden oluşan geri bildirim formları ile eğitim programını değerlendirmişlerdir. Her iki formda yer alan maddeler beşli ölçekle değerlendirilmiştir. Öğrenci geri bildirim formundaki ölçeğin güvenirlik $\alpha$ katsayıs1: 0.97, eğitici geri bildirim formunun güvenirlik katsayısı: 0.86 olarak bulunmuştur. Veriler SPSS 15.0 programı kullanılarak değerlendirilmiştir.

Bulgular: Beş y1llık süreçte tüm başlıklar için ortalamalar genel olarak 5 üzerinden 3 ve üzerindedir. 2015 yılında eğitici ve TUÖ geri bildirim formlarındaki dört ortak maddenin ortalamaları karşılaştırıldığında tüm maddelerde eğiticiler öğrencilerden yüksek puan vermişlerdir.

Sonuç: Beş y1llık süreçte öğrenci ve eğiticilerin sürdürülen uzmanlık eğitimi programını genel olarak olumlu buldukları anlaşılmaktadır. Göreli olarak en düşük puan alan "çalışma ortamı fiziki alt yapısı", "bölüm dışı rotasyonların eğitime katkısı", "anabilim dalında uzmanlık öğrencisi ile ilgili akademik kararlara katılım" ve "poliklinik eğitimine öğretim üyesi katkısı" başlıklarının ayrıntılı olarak araştırılmasının yararlı olacağı düşünülmektedir.

\section{MAKALE KÜNYE BILGIISI}

- Kaya, G.Ç., Koluaçık, Ş., Aktaş, N., \& Musal, B. (2018). Dokuz Eylül Üniversitesi Tıp Fakültesi Tıpta Uzmanlık Eğitimi Programlarına İlişkin Eğitici ve Öğrenci Geribildirimleri. Tıp Eğitimi Dünyası, (17)52, 5-13. 


\section{ABSTRACT:}

Background: Continuous and systematical evaluation of the educational program by students and trainers and the revision studies in the light of the obtained findings are crucial. In our Faculty residency training programs have been evaluated by students and trainers in every June with feedback forms developed by postgradute medical education program committee.

The purpose of this study is to present the findings of evaluation in the period of five years.

Methods: Students and trainers evaluated the educational program with thirty-item and sixitem feedback forms. Items were evaluated with five point scale.

Reliability coefficients of students ' and trainers' feedback forms were respectively 0.97 and 0.86 . The data was analysed with SPSS version 15.

Results: In the period of five year, the average scores of all items were above 3.00 points out of 5.00 points. In 2015, scores of four common items in students and trainers forms were compared. Trainers average scores were found higher than students

Conclusions: In general, students and trainers evaluated the educational program favourable in the five-year period. The items which had lowest points relatively; "physical working conditions", "contribution of external rotations to education", "participation to academic decisions related to the specialty students in departments" "trainers' contribution to outpatient clinic education" should be investigated in detailed.

\section{GíRiş}

Ülkemizde ve Dokuz Eylül Üniversitesi Tıp Fakültesi'nde tıpta uzmanlık eğitimi 26.04.2014 tarihinde yayınlanmış “Tıpta ve Diş
Hekimliğinde Uzmanlık Eğitimi Yönetmeliği”" kapsamında yürütülmektedir. Öğrenci ve eğiticilerin eğitim ile ilgili görüşlerinin alınarak değerlendirilmesi eğitim programında iyileştirmelerin yapılabilmesi, aksaklıkların problem oluşmadan çözümlenebilmesi, programlara bütün olarak bakılabilmesi gibi avantajlar sunmaktadır $(1,2) . \mathrm{Bu}$ nedenle Dokuz Eylül Üniversitesi Tıp Fakültesi'nde tıpta uzmanlık eğitiminin değerlendirilmesine yönelik olarak Dokuz Eylül Üniversitesi Tıp Fakültesi Mezuniyet Sonrası Eğitim Kurulu tarafından oluşturulmuş olan geri bildirim formları ile her yıl düzenli olarak eğitici ve öğrenci görüşleri alınarak tıpta uzmanlık eğitimi programları izlenmekte ve iyileştirme çalışmaları yapılmaktadır. Bu çalışmada beş yıllık süreçte program değerlendirme kapsamında alınan eğitici ve öğrenci geribildirim bulgularının paylaşılması amaçlanmaktadır.

\section{GEREÇ ve YÖNTEM}

Fakültemizde, Tıpta Uzmanlık Öğrencileri (TUÖ) ve eğiticiler için hazırlanmış iki adet geri bildirim formu kullanılmaktadır. TUÖ'nin kullandığı geri bildirim formları (3A formlar1); kuramsal eğitim etkinlikleri, eğitim etkinliklerine öğretim üyesi katkısı ve eğitim süreçleri boyutlarına ilişkin 30 maddeden oluşmaktadır. Eğiticilerin kullandığı geri bildirim formlarında (3B formları) ise kuramsal eğitim etkinlikleri, uygulamalı eğitim etkinlikleri, eğitim ortamının araç gereçler yönünden alt yapısı, eğitim ortamının fiziki alt yapısı, program hedeflerinin gerçekleşmesi ve eğitimin amacına ulaşması maddeleri yer almaktadır. Her iki formdaki maddelerin 1-5 (1:yetersiz, 3:orta,5:çok iyi) arasında ölçekle puanlanması istenmektedir. Mezuniyet Sonrası Eğitim Kurulu üyeleri tarafindan ilgili alan uzmanlarının görüşü alınarak geliştirilen 
formların güvenilirlik çalışması ilk uygulamada yapılmıştır. Öğrenci geri bildirim formunun güvenirlik $\alpha$ katsayısı:0.97, eğitici geri bildirim formunun güvenirlik $\alpha$ katsayısı:0.86 olarak bulunmuştur. Uzmanlık öğrenci işleri ve her anabilim dalı için belirlenmiş olan TUÖ temsilcisi tarafindan formlar her yil Haziran ayında dağıtılmış ve takibi TUÖ temsilcisi üzerinden sağlanmıştır. Formlar anonim olarak isim belirtmeksizin doldurulmuştur. Eğitici geribildirimleri ise anabilim dalı başkanlıkları üzerinden alınmıştır. $\mathrm{Bu}$ çalışmada 20112015 yılları arasında değerlendirilen formlara ilişkin bulgular yer almaktadır. Formların geri dönüş yüzdeleri TUÖ’den 2011-2015 yılları arasinda sirasiyla; 59.0, 50.0, 66.0, 50.8 ve 63.2; eğiticilerden ise farklı yıllarda $\% 80$ ve üzerinde olmuştur. Değerlendirilen form sayıları (n) Tablo 1 ve 2'de sunulmuştur. TUÖ'den form geri dönüş yüzdelerinin bazı yıllarda \%50'lerde olmasının çalışmanın temel kısıtlılığı olduğu düşünülmektedir.

2011-2015 y1lları arasında toplanan eğitici ve TUÖ geri bildirim formlarındaki veriler SPSS 15.0 programı kullanılarak değerlendirilmiştir. Tanımlayıcı istatistikler ve iki ortalama arasındaki farkın önemlilik testi kullanılmıştır.

\section{BULGULAR}

2011-2015 yılları arasında veri toplanan TUÖ'nin uzmanlık alanlarına göre dağılımı incelendiğinde \%2.8'inin temel bilimler, \%61.9'unun dahili bilimler, \%35.3'ünün ise cerrahi bilimler alanında uzmanlık eğitimlerini sürdürdükleri anlaşılmaktadır.

Tablo 1'de kuramsal eğitim etkinlikleri, eğitim etkinliklerine öğretim üyesi katkısı ve eğitim süreçleri boyutlarına ilişkin maddelere beş yıllık süreçte verilen TUÖ geribildirim puanlarının ortalamaları yer almaktadır. Mevcut 30 başlıktan yalnızca 2011 ve 2013 yıllarında "laboratuvar eğitimine öğretim üyesi katkısı" maddesinin ortalama puan1 5 üzerinden 2.93 ve 2.80 olup, farklı yıllarda diğer tüm maddelerin puan ortalamaları 5.00 üzerinden 3.00 ve üzerinde bulunmuştur.

Farklı uzmanlık alanlarında TUÖ'lerin "laboratuvar eğitimine öğretim üyesi katkısı" puanları incelendiğinde 2011 ve 2013 yıllarında temel bilimlerdeki puan ortalamasının sirasıyla 3.63 ve 3.00 ; dahili bilimlerde 2.98 ve 2.58 ; cerrahi bilimlerde ise 2.80 ve 3.10 olduğu anlaşılmıştır.

Karşılaştırılan başlıkların on ikisinde 2015 yılında 2011 yılına göre ortalama puanlarda anlamlı artış olduğu saptanmıştır $(\mathrm{p}<0.05)$.

Beş yıllık öğrenci geri bildirim puanlarının ortalaması incelendiğinde, en yüksek puan verilen başlıkların sırasıyla; "uzmanlık öğrencisi seminerleri”, "tez danışmanının eğitici desteği”, "olgu sayısının ve çeşitliliğinin müfredat hedeflerine ulaşmadaki yeterliği”, “eğitim danışmanının katkısı” olduğu anlaşılmaktadır. En düşük puan verilen başlıkların sırasıyla; “çalışma ortamı fiziki alt yapısı”, "bölüm dış1 rotasyonların eğitime katkısı", "anabilim dalında uzmanlık öğrencisi ile ilgili akademik kararlara katılım" ve "poliklinik eğitimine öğretim üyesi katkısı" olduğu saptanmıştır.

TUÖ’nin 2015 y1lında verdikleri geribildirim puanlarının uzmanlık alanlarına göre karşılaştırılması yapılmıştır. Temel bilimler uzmanlık öğrencileri az sayıda (\%2.8) olduğu için karşılaştırmaya dahil edilmemiştir. Dahili bilimler öğrencilerinin "teze ayrılan süre" maddesine verdikleri puanların cerrahi bilimler öğrencilerine göre anlamlı derecede yüksek olduğu (p:0.043), diğer maddelere verilen puanlarda uzmanlık alanları arasında anlamlı bir farklılık olmadığ 1 ( $>>0$. 05) saptanmıştır.

Tablo 2'de eğiticilerin verdikleri uzmanlık eğitimine ilişkin puan ortalamalarının farklı 
y1llarda 5.00 üzerinden 3.88 ve üzerinde olduğu anlaşılmaktadır. 2011-2015 yılları arasında eğitici geribildirim puanları karşılaş̧ırıldığında "kuramsal eğitim etkinlikleri”, "program hedeflerinin gerçekleşmesi" ve "eğitim programının genel olarak amacına ulaşması" maddelerine verilen puanlarda 2015 yılinda istatistiksel açıdan anlamlı bir artış saptanmıştır. Beş yıllık süreçteki ortalama puanlar incelendiğinde en yüksek puanların sırasıyla "kuramsal eğitim etkinlikleri" ve "uygulamalı eğitim etkinlikleri" maddesine verildiği, en düşük puanın ise "eğitim ortamı alt yapısı" maddesine verildiği anlaşılmaktadır.

Eğiticilerin 2015 yılında verdikleri puanların uzmanlık alanlarına göre karşılaştırılması yapıldığında dahili bilimlerde görev alan eğiticiler ile cerrahi bilimlerde görev yapan eğiticilerin puanlarında anlamlı fark saptanmamıştır $(\mathrm{p}>0.05)$.

2015 yllında eğitici ve öğrenci geri bildirim formlarındaki dört ortak maddenin karşılaştırması yapıldığında tüm maddelerde eğiticilerin verdikleri puanların öğrencilere göre istatistiksel açıdan anlamlı derecede yüksek olduğu saptanmıştır (Tablo 3).

\section{TARTIŞMA VE SONUÇ}

Beş yıllık süreçte TUÖ'nin eğitim etkinlikleri, öğretim üyesi katkısı ve eğitim süreçleri boyutlarını kapsayan 30 başlığa verdikleri puan ortalamalarının genel olarak orta değer olan 3.00 puan ve üzerinde olması dikkat çekmektedir. İki farklı yılda orta değerin altında puan verilen tek başl1k olan "laboratuvar eğitimine öğretim üyesi katkısı" maddesine farklı uzmanlık alanlarındaki öğrencilerin verdikleri puan ortalamaları incelendiğinde laboratuvar uygulamalarının gerçekleştiği temel bilimler alanındaki puan ortalamalarının orta değerin üzerinde olduğu anlaşılmıştır. On iki başlı̆̆ın puanlarında 2015 y1lında 2011 y1lına göre anlamlı artış olduğu görülmektedir.

Beş yıllık süreçteki puanların ortalaması incelendiğinde en yüksek puanların "uzmanlık öğrencisi seminerleri”, "tez danışmanının eğitici desteği”, "olgu sayısının, çeşitliliğinin müfredat hedeflerine ulaşmadaki yeterliği" ve "eğitim danışmanının katkısı" olması seminerlerin etkinliği, danışmanların katkısı ve gördükleri hasta sayısı ve çeşitliliğinin yeterliği konularındaki olumlu bakışlarını yansıtmaktadır. Türk Tabipleri Birliği tarafından yayınlanan Tipta Uzmanlık Eğitimi Raporu araştırma grubunda Devlet Üniversitelerindeki uzmanlık öğrencilerinin \%45.8'inin asistan eğitimine yönelik düzenli eğitim toplantıları yapıliyor mu sorusuna hayır yanitı verdikleri, \%49.6'sının mevcut eğitim kaynaklarını uzmanlık eğitimi için yetersiz buldukları ifade edilmektedir (3). Çalışmamızda en yüksek puan verilen başlığın uzmanlık öğrencisi seminerleri olması ve öğretim üyesi dersleri, seminerleri, olgu sunumu gibi kuramsal etkinliklere verilen puan ortalamalarının 5.00 üzerinden 3.363.65 arasında değişmesi kuramsal eğitimin yeterliği konusunda olumlu bir bulgu olarak değerlendirilmiştir.

En düşük puanların; "çalışma ortamı fiziki alt yapısı", "bölüm dışı rotasyonların eğitime katkısı", "anabilim dalında uzmanlık öğrencisi ile ilgili akademik kararlara katılım" ve "poliklinik eğitimine öğretim üyesi katkısı" olduğu anlaşılmaktadır. Bu başlıkların TUÖ'ne uygulanacak nicel ve nitel araştırmalarla ayrıntılı olarak değerlendirilmesinin uygun olacağı düşünülmektedir.

Dahili ve cerrahi bilimler uzmanlık alanlarındaki TUÖ'nin puanları arasında "teze ayrılan süre" maddesi dışında anlamlı farklılık bulunmamıştır. Cerrahi bilimlerdeki yoğunluk ve zaman baskısı nedeniyle bu başlığa verilen puanın daha düşük 
olduğu düşünülmektedir.

Eğiticilerin verdikleri olarak olumlu şekilde değerlendirdikleri anlaşılmaktadır. Ortak başliklar karşılaştırıldığında tüm başlıklarda eğiticilerin puanlarının öğrencilerden yüksek olduğu dikkat çekmektedir. Bu bulgu, fakültemizde eğitim programının değerlendirildiği farklı çalışmalarda eğitici puanlarının öğrencilerden daha yüksek bulunması $(4,5)$ ile paralellik göstermektedir. Eğiticilerin de en düşük puanı eğitim ortamı alt yapısı maddesine vermeleri bu başlığın ayrıntılı değerlendirilmesi gerekliliğini desteklemektedir.

$\mathrm{Bu}$ çalışmada yer alan bulgular anabilim dalları bazında programların geliştirilmesi amacına yönelik olarak ayrıntılı olarak ele alınarak değerlendirilmektedir.

Program değerlendirmede; eğitim programına ilişkin eğitici, öğrenci geribildirimlerinin alınması ve öğrencilerin katıldığı etkinliklerin sayısı, dağılımı, görülen hasta sayısı, yayın/ proje sayısı, işlem sayısı gibi eğitim çıktılarının değerlendirilmesi önem taşımaktadır (6). Fakültemizde TUÖ'in eğitimleri süresince gerçekleştirdikleri uygulamalı ve kuramsal etkinliklerin kayıt altına alınması ve izlenmesi amacıylae-karneyazılımı gerçekleştirilmiştir(7). Her yıl düzenli olarak alınan eğitici öğrenci geri bildirimi bulgularının, fakültemizde uygulanan e-karne verileri ile bir araya getirilerek eğitim programının tüm öğelerini kapsayan bir program değerlendirme çalışmasına dönüştürülmesinin yarar sağlayacağı düşünülmektedir.

\section{KAYNAKLAR}

1. Goldie J. AMEE Education Guide no.29: Evaluating Educational Programmes. Medical Teacher 2006; 28(3): 210-224.

2. Fyre AW, Hemmer PA. Program Evaluation
Models and Related Theories: AMEE Guide no.67. Medical Teacher 2012;34:e288-299.

3. Sayek İ, Aktan Ö, Demir T, Özyurt A. Tipta Uzmanlık Eğitimi Raporu, Türk Tabipleri Birliği Yayınları, Ankara, 2015.

4. Musal B, Taskiran C, Kelson A. Opinions of Tutors and Students about Effectiveness of PBL in Dokuz Eylul University School of Medicine. Medical Education Online 2003; 8:16.

5. Musal B, Kılınç O, Çapa Kaya G. Dokuz Eylül Üniversitesi Tip Fakültesi Klinik Eğitim Programı ve İşleyişine İlişkin Eğitici ve Öğrenci Görüşleri. Dokuz Eylül Üniversitesi Tıp Fakültesi Dergisi 2016;30 (3):125-130.

6. Musick D. A Conceptual Model For Program Evaluation in Graduate Medical Education. Academic Medicine 2006;81(8):759-765.

7. Kaya Ç, İkiz AÖ, Koyuncuoğlu C, Saban M, Yılmaz M, Olguner M, Tuncel P, Canda T. Tipta Uzmanlık Eğitiminde Cerrahi Tıp Bilimleri E-Karne Yazılımı. VIII.Ulusal Tıp Eğitimi Kongresi, 7-9 Mayıs 2014, İstanbul. 
Tablo 1. DEÜTF Tıpta Uzmanlık Öğrencilerinin Kuramsal Eğitim Etkinlikleri, Öğretim Üyesi

Katkısı ve Eğitim Süreçlerine İlişkin Değerlendirmeleri *

\begin{tabular}{|c|c|c|c|c|c|c|c|}
\hline $\begin{array}{l}\text { DEĞERLENDİRIILEN } \\
\text { BAŞLIKLAR }\end{array}$ & $\begin{array}{l}2011 \\
\mathrm{n}: 266\end{array}$ & $\begin{array}{l}2012 \\
\mathrm{n}: 261\end{array}$ & $\begin{array}{l}2013 \\
\mathrm{n}: 351\end{array}$ & $\begin{array}{l}2014 \\
\mathrm{n}: 249\end{array}$ & $\begin{array}{l}2015 \\
n: 318\end{array}$ & $\begin{array}{l}\text { Ort } \\
\mathrm{n}: 1445\end{array}$ & $\begin{array}{l}\mathrm{P} * * \\
2011- \\
2015\end{array}$ \\
\hline Kuramsal eğitim etkinlikleri & 3.30 & 3.36 & 3.23 & 3.64 & 3.48 & 3.39 & $>0.05$ \\
\hline Öğretim üyesi dersleri /seminerleri & 3.24 & 3.51 & 3.38 & 3.72 & 3.49 & 3.46 & 0.013 \\
\hline Uzmanlık öğrencisi seminerleri & 3.61 & 3.58 & 3.57 & 3.84 & 3.67 & 3.65 & $>0.05$ \\
\hline Multidisipliner toplantılar & 3.26 & 3.29 & 3.18 & 3.50 & 3.58 & 3.36 & $>0.05$ \\
\hline $\begin{array}{l}\text { Diğer kuramsal etkinlikler (Olgu } \\
\text { sunumu, dergi s) }\end{array}$ & 3.47 & 3.49 & 3.36 & 3.60 & 3.59 & 3.49 & $>0.05$ \\
\hline $\begin{array}{l}\text { Eğitim etkinliklerine öğretim üyesi } \\
\text { katkısı }\end{array}$ & 3.43 & 3.35 & 3.36 & 3.57 & 3.66 & 3.49 & 0.043 \\
\hline $\begin{array}{l}\text { Hasta başı eğitimine öğretim üyesi } \\
\text { katkıs1 }\end{array}$ & 3.07 & 3.15 & 3.09 & 3.31 & 3.29 & 3.18 & 0.048 \\
\hline $\begin{array}{l}\text { Poliklinik eğitimine öğretim üyesi } \\
\text { katkıs1 }\end{array}$ & 3.03 & 3.06 & 3.00 & 3.22 & 3.43 & 3.15 & 0.001 \\
\hline $\begin{array}{l}\text { Cerrahi/girişimsel eğitime öğretim } \\
\text { üyesi katkısı }\end{array}$ & 3.20 & 3.18 & 3.10 & 3.01 & 3.32 & 3.17 & $>0.05$ \\
\hline $\begin{array}{l}\text { Acil hasta yönetiminde öğretim üyesi } \\
\text { katkısı }\end{array}$ & 3.35 & 3.14 & 3.11 & 3.25 & 3.38 & 3.24 & $>0.05$ \\
\hline $\begin{array}{l}\text { Laboratuvar eğitimine öğretim üyesi } \\
\text { katkıs1 }\end{array}$ & 2.93 & 3.00 & 2.80 & 3.09 & 3.25 & 3.01 & 0.006 \\
\hline $\begin{array}{l}\text { Konsültasyon sırasında eğitime } \\
\text { ögretim üyesi katkısı }\end{array}$ & 3.29 & 3.21 & 3.24 & 3.32 & 3.51 & 3.31 & 0.040 \\
\hline Eğitim danışmanının katkısı & 3.43 & 3.54 & 3.40 & 3.63 & 3.65 & 3.53 & $>0.05$ \\
\hline Tez danışmanının eğitici desteği & 3.41 & 3.59 & 3.50 & 3.87 & 3.81 & 3.63 & 0.000 \\
\hline $\begin{array}{l}\text { Anabilim dalındaki tüm eğiticilerin } \\
\text { eğitime katkısı }\end{array}$ & 3.39 & 3.37 & 3.33 & 3.55 & 3.54 & 3.43 & $>0.05$ \\
\hline Eğitim süreçleri & 3.31 & 3.37 & 3.26 & 3.43 & 3.62 & 3.42 & 0.009 \\
\hline Teze ayrilan süre & 3.18 & 3.60 & 3.17 & 3.46 & 3.59 & 3.39 & 0.000 \\
\hline $\begin{array}{l}\text { Anabilim dalında geribildirim } \\
\text { süreçlerinin ișletilmesi }\end{array}$ & 3.24 & 3.33 & 3.13 & 3.29 & 3.51 & 3.30 & 0.008 \\
\hline $\begin{array}{l}\text { Anabilim dalında uzmanlık öğrencisi } \\
\text { ile ilgili akademik kararlara katılım }\end{array}$ & 3.06 & 3.08 & 3.00 & 3.14 & 3.41 & 3.14 & 0.001 \\
\hline $\begin{array}{l}\text { Bölüm içi rotasyonların eğitime } \\
\text { katkısı }\end{array}$ & 3.42 & 3.47 & 3.53 & 3.42 & 3.75 & 3.53 & 0.028 \\
\hline $\begin{array}{l}\text { Bölüm dışı rotasyonların eğitime } \\
\text { katkısı }\end{array}$ & 3.20 & 3.04 & 3.00 & 3.19 & 3.33 & 3.14 & $>0.05$ \\
\hline Nöbetlerin eğitime katkısı & 3.37 & 3.36 & 3.19 & 3.35 & 3.56 & 3.36 & $>0.05$ \\
\hline
\end{tabular}




\begin{tabular}{|c|c|c|c|c|c|c|c|}
\hline $\begin{array}{l}\text { Olgu sayısının müfredat hedeflerine } \\
\text { ulastırmada yeterliliği }\end{array}$ & 3.53 & 3.51 & 3.44 & 3.63 & 3.65 & 3.55 & $>0.05$ \\
\hline $\begin{array}{l}\text { Olgu çeșitliliğinin müfredat } \\
\text { hedeflerine ulasstırmada yeterliği }\end{array}$ & 3.47 & 3.55 & 3.46 & 3.61 & 3.63 & 3.54 & $>0.05$ \\
\hline $\begin{array}{l}\text { Eğitim ortamı alt yapisı (tıbbi araç ve } \\
\text { gereçler) }\end{array}$ & 3.45 & 3.38 & 3.27 & 3.35 & 3.39 & 3.36 & $>0.05$ \\
\hline $\begin{array}{l}\text { Eğitim ortamı fiziki alt yapıs1 } \\
\text { (kütüphane, bs vb) }\end{array}$ & 3.32 & 3.15 & 3.14 & 3.19 & 3.15 & 3.19 & $>0.05$ \\
\hline $\begin{array}{l}\text { Calışma ortamı fiziki alt yapısı (nöbet } \\
\text { odası vb.) }\end{array}$ & 3.15 & 3.08 & 3.12 & 3.12 & 3.06 & 3.10 & $>0.05$ \\
\hline $\begin{array}{l}\text { Eğitim sürecinin uzmanlık öğrencisi } \\
\text { çalışma rehberlerine uygunluğu }\end{array}$ & 3.34 & 3.38 & 3.26 & 3.44 & 3.43 & 3.36 & $>0.05$ \\
\hline $\begin{array}{l}\text { Uzmanlık ögrencisi etkinlik kayıt } \\
\text { defterinin kullanımı }\end{array}$ & 3.17 & 3.19 & 3.17 & 3.29 & 3.29 & 3.22 & $>0.05$ \\
\hline $\begin{array}{l}\text { Gerçekleştirilen eğitim programı ile } \\
\text { ilgili genel değerlendirme }\end{array}$ & 3.40 & 3.38 & 3.34 & 3.57 & 3.59 & 3.46 & $>0.05$ \\
\hline
\end{tabular}

*Tıpta uzmanlık öğrencilerinden her maddeye 1-5 (1:yetersiz, 2:ortanın altı, 3:orta, 4:iyi, 5:çok

iyi) puan vermeleri istenmiştir.

** İki ortalama arasındaki farkın önemlilik testi 
Tablo 2. DEÜTF Eğiticilerinin Verdikleri Tıpta Uzmanlık Eğitimine İlişkin Görüşleri *

\begin{tabular}{|l|l|l|l|l|l|l|l|}
\hline DEĞERLENDíRILEN BAŞLIKLAR & $\begin{array}{l}\mathbf{2 0 1 1} \\
\mathbf{n}: \mathbf{2 6 9}\end{array}$ & $\begin{array}{l}\mathbf{2 0 1 2} \\
\mathbf{n}: \mathbf{2 6 6}\end{array}$ & $\begin{array}{c}\mathbf{2 0 1 3} \\
\mathbf{n}: \mathbf{2 4 4}\end{array}$ & $\begin{array}{l}\mathbf{2 0 1 4} \\
\mathbf{n}: \mathbf{2 3 2}\end{array}$ & $\begin{array}{c}\mathbf{2 0 1 5} \\
\mathbf{n}: \mathbf{2 8 3}\end{array}$ & $\begin{array}{c}\text { Ort } \\
\mathbf{n}: \mathbf{1 2 9 4}\end{array}$ & $\begin{array}{c}\mathbf{P}^{* *} \\
\mathbf{2 0 1 1} \\
\mathbf{2 0 1 5}\end{array}$ \\
\hline $\begin{array}{l}\text { Kuramsal eğitim etkinlikleri (Sunum, } \\
\text { seminer, dergi saati, toplantılar vb.) }\end{array}$ & 4.18 & 4.25 & 4.23 & 4.22 & 4.38 & 4.26 & 0.002 \\
\hline $\begin{array}{l}\text { Uygulamalı eğitim etkinlikleri } \\
\text { (Ameliyatlar, girişimler, laboratuvar } \\
\text { uygulamaları) }\end{array}$ & 4.15 & 4.13 & 4.02 & 4.15 & 4.24 & 4.14 & $>0.05$ \\
\hline $\begin{array}{l}\text { Eğitim ortamı alt yapısı (Tibbi araç ve } \\
\text { gereçler) }\end{array}$ & 4.04 & 3.98 & 3.94 & 3.88 & 4.05 & 3.98 & $>0.05$ \\
\hline $\begin{array}{l}\text { Eğitim ortamı fiziki alt yapısı } \\
\text { (Kütüphane, bilgisayar vb.) }\end{array}$ & 4.04 & 4.02 & 4.04 & 3.93 & 4.12 & 4.03 & $>0.05$ \\
\hline Program hedeflerinin gerçekleșmesi & 4.00 & 4.02 & 4.07 & 4.04 & 4.22 & 4.07 & 0.002 \\
\hline $\begin{array}{l}\text { Eğitim Programının bir bütün olarak } \\
\text { amacina ulaşması }\end{array}$ & 4.04 & 4.06 & 4.04 & 4.09 & 4.26 & 4.10 & 0.001 \\
\hline
\end{tabular}

${ }^{*}$ Eğiticilerden her maddeye 1-5 (1:yetersiz, 2:ortanın alth, 3:orta, 4:iyi, 5:çok iyi) puan vermeleri istenmiş̧tir.

** İki ortalama arasındaki farkın önemlilik testi 
Tablo 3. Eğitici ve Öğrenci Görüşleri Karşllaştırması -2015*

\begin{tabular}{|c|c|c|c|}
\hline DEĞERLENDİRİLEN BAŞLIKLAR & $\begin{array}{l}\text { Eğitici Puan } \\
\text { Ort.** }\end{array}$ & $\begin{array}{l}\text { TUÖ } \\
\text { Puan } \\
\text { Ort** }\end{array}$ & $\begin{array}{l}\text { İstatistiksel } \\
\text { analiz*** }\end{array}$ \\
\hline $\begin{array}{l}\text { Kuramsal eğitim etkinlikleri } \\
\text { (Sunum, seminer, dergi saati, toplantılar vb.) }\end{array}$ & 4.41 & 3.47 & 0.000 \\
\hline $\begin{array}{l}\text { Eğitim ortamı alt yapısı } \\
\text { (Tıbbi araç ve gereçler) }\end{array}$ & 4.04 & 3.45 & 0.000 \\
\hline $\begin{array}{l}\text { Eğitim ortamı fiziki alt yapısı } \\
\text { (Kütüphane, bilgisayar vb.) }\end{array}$ & 4.11 & 3.14 & 0.000 \\
\hline $\begin{array}{l}\text { Eğitim Programının bir bütün olarak amacına ulaşması / } \\
\text { Gerçekleştirilen eğitim programı ile ilgili genel değerlendirme }\end{array}$ & 4.25 & 3.52 & 0.000 \\
\hline
\end{tabular}

*2015 yılında eğitici ve öğrenci geribildirim formlarındaki ortak başlıklara verilen puan ortalamaları incelenmiştir

**Eğiticilerden ve tıpta uzmanlık öğrencilerinden her maddeye 1-5 (1:yetersiz, 2:ortanın altı, 3:orta, 4:iyi, 5:çok iyi) puan vermeleri istenmiştir

*** İki ortalama arasındaki farkın önemlilik testi 